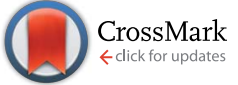

Cite this: Chem. Sci., 2015, 6, 3868

\title{
How to determine accurate chemical ordering in several nanometer large bimetallic crystallites from electronic structure calculations $\uparrow$
}

\begin{abstract}
Sergey M. Kozlov, ${ }^{a}$ Gábor Kovács, ${ }^{a}$ Riccardo Ferrando ${ }^{b}$ and Konstantin M. Neyman ${ }^{\star a c}$
Chemical and physical properties of binary metallic nanoparticles (nanoalloys) are to a great extent defined by their chemical ordering, i.e. the pattern in which atoms of the two elements are located in a given crystal lattice. The reliable determination of the lowest-energy chemical ordering is a challenge that impedes indepth studies of several-nm large bimetallic particles. We propose a method to efficiently optimize the chemical ordering based solely on results of electronic structure (density functional) calculations. We show that the accuracy of this method is practically the same as the accuracy of the underlying quantum mechanical approach. This method, due to its simplicity, immediately reveals why one or another chemical ordering is preferred and unravels the nature of the binding within the nanoparticles. For instance, our results provide very intuitive understanding of why gold and silver segregate on lowcoordinated sites in $\mathrm{Pd}_{70} \mathrm{Au}_{70}$ and $\mathrm{Pd}_{70} \mathrm{Ag}_{70}$ particles, while $\mathrm{Pd}_{70} \mathrm{Cu}_{70}$ exhibits matryoshka-like structure and $\mathrm{Pd}_{70} \mathrm{Zn}_{70}$ features $\mathrm{Zn}$ and $\mathrm{Pd}$ atoms arranged in layers. To illustrate the power of the new method we optimized the chemical ordering in much larger $\mathrm{Pd}_{732} \mathrm{Au}_{731}, \mathrm{Pd}_{732} \mathrm{Ag}_{731}, \mathrm{Pd}_{732} \mathrm{Cu}_{731}$, and $\mathrm{Pd}_{732} \mathrm{Zn}_{731}$ nanocrystals, whose size $\sim 4.4 \mathrm{~nm}$ is common for catalytic applications.
\end{abstract}

Received 29th October 2014

Accepted 1st April 2015

DOI: $10.1039 / c 4 s c 03321 \mathrm{c}$

www.rsc.org/chemicalscience composition is a part of the so-called global optimization problem..$^{2,3}$ Although numerous techniques have been developed to treat this extremely difficult problem, even nowadays global optimization of only relatively small clusters is feasible.

Another part of the global optimization problem is the search for the lowest-energy chemical ordering, that is, the location of atoms of different elements within a given geometric structure. Chemical ordering governs such NP properties as surface composition and electronic structure, which are crucial for surface reactivity and heterogeneous catalysis. ${ }^{4} \mathrm{~A}$ rich variety of chemical ordering patterns can be found in nanoalloys: from ordered phases and solid solutions through core-shell and multishell arrangements to phase-separated quasi-Janus particles. As a rule, strong heteroatomic bonds and charge transfer between atoms of various metals tend to favor well-mixed structures, while big differences in atomic sizes and surface energies of the metals facilitate surface segregation. ${ }^{2}$ Despite the fact that recent advances in electron microscopy techniques have allowed the visualization of individual atoms in bimetallic NPs, it is still hard to derive three-dimensional chemical ordering solely based on experimental data. Therefore, predicting the most thermodynamically stable chemical ordering theoretically is of great importance.

This task is extremely difficult, because the number of possible inequivalent arrangements of atoms of different types within a given geometric structure (i.e. the number of the socalled homotops) is enormously big. ${ }^{2}$ For instance, for a binary alloy particle consisting of $\mathrm{N}$ atoms, $\mathrm{A}_{Y} \mathrm{~B}_{N-Y}$, the total number of 
homotops is $N ! / Y !(N-Y !)$, which for $Y=N / 2$ is approximately $2^{N+1 / 2} / \sqrt{\pi N}$ (including structures equivalent by symmetry). This renders the complete exploration of the homotop landscape unfeasible already for NPs of a few dozens of atoms. At the same time, NPs that are relevant to chemical experiments and practical applications very often contain from several hundred to several thousand atoms.

In order to deal with this formidable problem, intelligent search algorithms combined with reliable energetic models are indispensable. Efficient search algorithms that can explore the low-energy part of the homotop landscape have been developed recently..$^{5-8}$ However, these algorithms can be used in the relevant size range only within simplified energetic models, ${ }^{\mathbf{9}, 10}$ since $a b$ initio search procedures are by far too tedious. Nowadays, state-of-the-art $a b$ initio searches are still limited to alloy clusters with a few dozens of atoms, ${ }^{3}$ despite that much bigger NPs can be routinely calculated by density functional theory methods (DFT). ${ }^{\mathbf{1 1 - 1 4}}$

Simplified approaches to calculate energy of particles comprise atomistic interaction potentials and lattice models. Reliable interatomic potentials are now available for some phase-separating systems ${ }^{\mathbf{1 5}-\mathbf{1 9}}$ and for certain systems making solid solutions, ${ }^{\mathbf{2 0 , 2 1}}$ while their accuracy is often limited when dealing with systems forming ordered phases. ${ }^{22}$ Generally speaking, the reliability of atomistic approaches for nanostructured materials is system-dependent and cannot be predicted a priori. Rather, it needs to be examined for each case against higher-level calculations. Furthermore, lattice models depend on a set of energetic parameters that are often fitted on bulk or surface quantities obtained by experiments or ab initio calculations by ad hoc procedures. ${ }^{23-25}$

Here we propose a general and systematic method for developing lattice models that aims at transferring $a b$ initio or DFT level of accuracy to NP sizes that are relevant to experiments and practical applications. This method is based on the analysis of energy related to topological degrees of freedom, $E_{\mathrm{TOP}}$, which is reminiscent of model Hamiltonians in the Ising model ${ }^{26}$ or the cluster expansion method. ${ }^{27}$ Topological degrees of freedom used in this work take into account (1) the formation of heteroatomic bonds, (2) the different coordination of atoms in different positions of a NP, and (3) the possible tetragonal distortion in $\mathrm{L} 1_{0}$ alloys. The parameters in the energy expression for each NP size and composition are derived by a rigorous fitting procedure based on energies, $E_{\mathrm{ES}}$, from a limited set of density functional (electronic structure) calculations for NPs of the same size and composition. The inherently physical origin of the fitted parameters allows one to directly rationalize the nature of binding in the considered alloys. The accuracy and precision of the employed approach were assessed and found to be sufficient to obtain realistic models.

Herein, the chemical ordering in $\mathrm{Pd}_{70} \mathrm{X}_{70}$ NPs of fcc structure for $\mathrm{X}=\mathrm{Au}, \mathrm{Ag}, \mathrm{Cu}$ and tetragonal $\mathrm{L} 1_{0}$ structure for $\mathrm{X}=\mathrm{Zn}$ has been optimized employing the proposed method. Note that unsupported transition metal NPs of this size were shown to be representative models for catalytic studies. ${ }^{28-30}$ In order to ensure finding the lowest-energy homotops, we used a multiple exchange algorithm, which allowed us to overcome very big energy barriers in the configurational space of certain NPs. In principle, one would expect bulk segregation of Pd in all these structures, since Pd has the highest surface energy among the considered metals. ${ }^{31,32}$ Nevertheless, only for $\mathrm{Pd}-\mathrm{Au}$ and $\mathrm{Pd}-\mathrm{Ag}$ we found high stability of the segregated structures, while $\mathrm{Pd}-\mathrm{Cu}$ and Pd-Zn exhibited more complex morphologies. We also performed the fitting of topological energies for $\mathrm{Pd}_{79-Y} \mathrm{Au}_{Y}$ and $\mathrm{Pd}_{140-Y} \mathrm{Au}_{Y}$ and found that the $E_{\text {TOP }}$ expressions depend much less on the NP size than on the composition. This observation allowed us to apply the topological expressions obtained for $\mathrm{Pd}_{70} \mathrm{X}_{70}$ NPs ( $\mathrm{X}=\mathrm{Au}, \mathrm{Ag}, \mathrm{Cu}$ and $\mathrm{Zn}$ ) to the optimization of the chemical ordering in the respective $4.4 \mathrm{~nm}$ big $\operatorname{Pd}_{732} \mathrm{X}_{731}$ NPs, illustrating the power of the proposed approach.

Note that the proposed energy expressions are extendable to account for other contributions, due to e.g. NP-support or NPadsorbate interactions. This makes the presented method very promising for studies of bimetallic NPs with experimentally accessible sizes in experimentally relevant conditions.

\section{Results and discussion}

\section{Methodology: optimization of chemical ordering in nanoalloys}

The idea of topological energies was inspired by the observation that in bimetallic NPs $\mathrm{A}_{Y} \mathrm{~B}_{N-Y}$ atoms of one element often prefer to occupy interior sites in the most stable structures, while atoms of the other element tend to stay at low-coordinated surface sites. ${ }^{2,33}$ The formation of heteroatomic bonds and layered structures during the alloying process is also known to be important. To quantify these trends we considered the following form of topological energies, $E_{\mathrm{TOP}}$, that depend only on the mutual positions of atoms of types A and B within a predetermined lattice,

$$
\begin{aligned}
E_{\mathrm{TOP}}= & E_{0}+\varepsilon_{\mathrm{BOND}}^{\mathrm{A}-\mathrm{B}} N_{\mathrm{BOND}}^{\mathrm{A}-\mathrm{B}}+\varepsilon_{\mathrm{CORNER}}^{\mathrm{A}} N_{\mathrm{CORNER}}^{\mathrm{A}}+\varepsilon_{\mathrm{EDGE}}^{\mathrm{A}} N_{\mathrm{EDGE}}^{\mathrm{A}} \\
& +\varepsilon_{\mathrm{TERRACE}}^{\mathrm{A}} N_{\mathrm{TERRACE}}^{\mathrm{A}}+\varepsilon_{\mathrm{LAYER}} N_{\mathrm{LAYER}} .
\end{aligned}
$$

Here, $E_{0}$ is a constant (for a given particle $\mathrm{A}_{Y} \mathrm{~B}_{N-Y}$ ) required to minimize the offset between $E_{\mathrm{TOP}}$ and energies of the electronic structure calculations, $E_{\mathrm{ES}} ; N_{\mathrm{BOND}}^{\mathrm{A}-\mathrm{B}}$ - number of heteroatomic bonds (nearest-neighbor A-B pairs of atoms) in the considered structure; $N_{\text {CORNER }}^{\mathrm{A}}, N_{\mathrm{EDGE}}^{\mathrm{A}}$ and $N_{\text {TERRACE }}^{\mathrm{A}}$ numbers of atoms of type A on corners, edges and terraces, respectively. Other parameters, such as $N_{\mathrm{BOND}}^{\mathrm{A}-\mathrm{A}}, N_{\mathrm{BOND}}^{\mathrm{B}-\mathrm{B}}$ or $N_{\mathrm{CORNER}}^{\mathrm{B}}, N_{\mathrm{EDGE}}^{\mathrm{B}}$, and $N_{\text {TERRACE }}^{\mathrm{B}}$ as well as $N_{\text {INTERIOR }}^{\mathrm{A}}$ depend linearly on the employed parameters for a given NP size and composition. Thus, they were not included in the $E_{\mathrm{TOP}}$ expression. The term $N_{\text {LAYER }}=\sum_{\text {LAYERS }}\left|n_{j}^{\mathrm{A}}-n_{j}^{\mathrm{B}}\right|$ accounts for possible atomic arrangements in monometallic layers and concomitant tetragonal distortion of nanoparticle's lattice. $n_{j}^{\mathrm{A}}$ and $n_{j}^{\mathrm{B}}$ are the numbers of atoms $\mathrm{A}$ and atoms $\mathrm{B}$, respectively, in layer $j$ of a NP and the sum is taken over all layers. $\left|n_{j}^{\mathrm{A}}-n_{j}^{\mathrm{B}}\right|$ is maximal for layers composed entirely of atoms A or B and is close to zero for layers composed of both atoms in equal proportions.

In eqn (1) $\varepsilon_{i}$ are energetic parameters associated with each degree of freedom $N_{i}$ considered in the topological energy. They 
will be referred to as descriptors. In contrast to parameters in many empirical methods, each descriptor $\varepsilon_{i}$ has a clear physical meaning. For instance, $\varepsilon_{\mathrm{BOND}}^{\mathrm{A}-\mathrm{B}}$ is related to the energy gain caused by the mixing of two metals. For example, the formation (mixing) energy of ordered $\mathrm{L}_{0} \mathrm{~A}_{0.5} \mathrm{~B}_{0.5}$ bulk alloy from separated bulk $\mathrm{A}$ and bulk $\mathrm{B}$ is $4 \varepsilon_{\mathrm{BOND}}^{\mathrm{A}-\mathrm{B}}$ per atom, since in this alloy each atom forms 8 heteroatomic bonds and each bond connects two atoms. In turn, $\varepsilon_{\text {CORNER }}^{\mathrm{A}}$ is the energy required for or gained from the exchange of an atom of type A on the corner with an atom of type B in the NP interior (given that the number of heteroatomic bonds remains constant). $\varepsilon_{\text {LAYER }}$ is a descriptor associated with the formation of layers in (tetragonally distorted) $\mathrm{L} 1_{0}$ structure; the latter is favored when $\varepsilon_{\mathrm{LAYER}}<0$. Note that for $\mathrm{Au}-\mathrm{Pd}, \mathrm{Ag}-\mathrm{Pd}$ and $\mathrm{Cu}-\mathrm{Pd}$ alloys $\varepsilon_{\text {LAYER }}$ values were calculated to be zero within statistical accuracy. Hence, the term $\varepsilon_{\text {LAYER }} \sum_{\text {LAYERS }}\left|n_{j}^{\mathrm{A}}-n_{j}^{\mathrm{B}}\right|$ was neglected for description of these materials, which did not affect the accuracy of the $E_{\text {TOP }}$ expression. The model Hamiltonian that leads to the topological energy expression (1) for bimetallic nanocrystals with fcc structure is presented in the ESI. $\dagger$

For each nanocrystal with a given shape, size and composition, an individual topological energy expression is tailored via fitting the descriptors $\varepsilon_{i}$ to the DFT total energy $E_{\mathrm{ES}}$ values of various homotops of this particular NP (obtained via local geometry optimization at DFT level). This way of fitting leads to a rather high accuracy of this approach compared to e.g. interatomic potentials despite the more complex structure of the latter with many more fitting parameters. Naturally, this way of fitting leads to different topological expressions for nanoparticles of different shape, size and composition. However, since each of these descriptors $\varepsilon_{i}$ determines certain interactions, changes in their values from system to system directly reflect the underlying changes in material properties.

In this work we calculated DFT energies $E_{\mathrm{ES}}$ of 28 to 127 homotops to fit $E_{\mathrm{TOP}}$ for every considered NP shape and composition via multiple linear regression. ${ }^{34}$ When several structures with the same set of $N_{i}$ were present in the fitting set, only the structure with the lowest $E_{\mathrm{ES}}$ was taken for the fitting. The electronic structure calculations of $E_{\mathrm{ES}}$ for $N_{\mathrm{FIT}}$ NP structures required for the fitting is the most computationally demanding part of the method. Therefore, one should aim to keep the number of DFT calculations at a minimum. Nevertheless, we have to point out that insufficient size of the fitting set would lead to overfitting and poor statistical accuracy of the obtained descriptors $\varepsilon_{i}$. The accuracy can be estimated as $95 \%$ confidence intervals via the bootstrap method. ${ }^{35}$ This method was applied since it seamlessly takes into account that $\varepsilon_{i}$ are not independent statistical quantities and may strongly correlate with each other. In practice, descriptors that significantly contribute to $E_{\mathrm{TOP}}$ have rather small inaccuracies, while those not crucial for the fitting are determined less accurately. Note that the inaccuracy of the descriptors does not reflect the inaccuracy of the energy expression as a whole.

The precision of the topological expressions themselves was estimated as twice the residual standard deviation (RSD) $\delta$ between $E_{\mathrm{ES}}$ and $E_{\mathrm{TOP}}$ energies for a set of $N_{\mathrm{TEST}} \geq 10$ structures not included in the fitting procedure

$$
\delta=2 \sqrt{\frac{\sum\left(E_{\mathrm{ES}}-E_{\mathrm{TOP}}\right)^{2}-\left(\sum\left(E_{\mathrm{ES}}-E_{\mathrm{TOP}}\right)\right)^{2} / N_{\mathrm{TEST}}}{N_{\mathrm{TEST}}-1} .}
$$

According to this definition, (relative) $E_{\mathrm{TOP}}$ values are within $\delta$ from the respective (relative) $E_{\mathrm{ES}}$ values with $>95 \%$ probability. In turn, the accuracy (trueness) of the topological energies, $\Delta E$, was estimated as the energy difference between the lowestenergy structure according to the ES calculations and the global minimum structure within the topological energy optimization. Since many homotops yield the same $E_{\mathrm{TOP}}$ value but somewhat different $E_{\mathrm{ES}}$, the energy difference $\Delta E$ was calculated by the topological expression to avoid any arbitrariness.

Once descriptors in eqn (1) for a given system are determined, one may use this formula to perform optimization of the chemical ordering within the predetermined lattice. In this work, we carried out Monte-Carlo simulations with only one kind of moves - simultaneous exchange of $n$ random atoms of element A with $n$ random atoms of element $\mathrm{B}$. The number of atoms to be exchanged was chosen randomly with the probability $p(n) \sim n^{-3 / 2}$, which yields the probability of single exchange moves for big NPs around $1 / \zeta(3 / 2) \sim 38 \%$, where $\zeta$ is the Riemann zeta function. This method makes it possible to overcome very big energy barriers that exist, e.g. in the configurational space of Pd-Zn NPs (see the respective discussion in Pd-Zn section).

The temperature in a Monte-Carlo simulation was chosen in such a way that a system spends $<50 \%$ of time in the lowestenergy configuration. A configuration of $\mathrm{A}_{Y} \mathrm{~B}_{N-Y} \mathrm{NP}$ was considered a global minimum, if a move from it to a lower energy structure failed after $10 Y(N-Y)$ multiple exchange moves. This means that we applied every possible one of $Y(N-$ $Y$ ) single exchange moves for the global minimum search with probability of

$$
1-\left(1-\frac{1}{Y(N-Y)}\right)^{0.38 \times 10 Y(N-Y)} \sim 1-\mathrm{e}^{-3.8}=98 \%
$$

and we could not find a structure of lower energy.

The code that performs Monte-Carlo simulations was written in a way that whenever it finds a structure with lower energy than the previously calculated ones, the geometry is recorded. Out of these structures, $N_{\mathrm{TEST}}$ structures with the lowest $E_{\mathrm{TOP}}$ energies were calculated by the chosen ES technique, and their ES energies were used to estimate the precision of the topological energy approach employed in the Monte-Carlo simulation. Thus, the test sets included rather diverse low-energy structures ranging from the predicted global minimum to structures located $\sim N_{\text {TEST }}$ multiple exchange moves far from it in the configurational space. If we wanted to improve the precision $\delta$ of the $E_{\mathrm{TOP}}$ estimated using this test set, then the test set was added to the fitting set and new descriptors were obtained. As a result of the global optimization with the new energy expression, a new test set was generated in the fashion 
described above and the precision of the new $E_{\mathrm{TOP}}$ expression was estimated on the new test set, which had not yet been included in the fitting.

Such way of fitting allows for a better description of lowenergy structures (prevailing in the fitting set). It suits the purpose of global optimization focusing on finding the structure with the lowest possible energy. In the cases where calculated high-energy structures are qualitatively different from lowenergy homotops, one may consider deliberately removing high-energy structures from the fitting in order to further improve the description of low-energy structures. One of such cases could be alloys of metals with considerably different atomic sizes, where high-energy and low-energy homotops may have notably different geometric structures due to the mechanical stress and concomitant relaxation.

The Monte-Carlo scheme also allows one to estimate thermal energy associated with the Boltzmann population of different homotops for a given NP structure. Thermal energies calculated in such a way (with fixed atomic positions) are used only to inspect the magnitude of chemical disorder at finite temperature and to put precision $\delta$ of the proposed approach into perspective. Other contributions to the thermal energy may be much bigger and, thus, more important. Nevertheless, they are not relevant to the analysis performed herein.

In the present work we applied the just outlined method to the optimization of chemical ordering in PdAu, PdAg and PdCu NPs with fcc lattices as well as in PdZn NPs with tetragonally distorted $\mathrm{L} 1_{0}$ lattice. It is important to emphasize that having slightly modified topological energy expression and/or electronic structure calculations one may apply the proposed method to a variety of materials, crystalline structures and reaction conditions. For instance, one may substitute $\varepsilon_{\text {TERRACE }}^{\mathrm{A}} N_{\text {TERRACE }}^{\mathrm{A}}$ in (1) by $\varepsilon_{\{111\}}^{\mathrm{A}} N_{\{111\}}^{\mathrm{A}}$ and $\varepsilon_{\{100\}}^{\mathrm{A}} N_{\{100\}}^{\mathrm{A}}$ to account separately for segregation on $\{111\}$ and $\{100\}$ facets in NPs of certain shapes. Similar modifications can be done to distinguish different kinds of edges and corners. To account for NPsupport interactions one may add the term $\varepsilon_{\text {INTERFACE }}^{\mathrm{A}} N_{\text {INTERFACE }}^{\mathrm{A}}$ to eqn (1) to describe support-induced segregation on the interface. In order to account for the reaction atmosphere there is no need to change the $E_{\mathrm{TOP}}$ expression at all: it is sufficient to consider the presence of adsorbates in the respective electronic structure calculations. Extension of the method to handle arrays of heterometallic NPs (e.g. like the monometallic arrays $\left.{ }^{36}\right)$ is also straightforward.

\section{Pd-Au}

Alloys of $\mathrm{Au}$ and $\mathrm{Pd}$ have been intensively studied ${ }^{37,38}$ due to their numerous actual and potential applications in heterogeneous catalysis. They include $\mathrm{H}_{2} \mathrm{O}_{2}$ synthesis, ${ }^{39} \mathrm{CH}_{4}$ conversion to methanol, ${ }^{40} \mathrm{C}-\mathrm{C}$ coupling, ${ }^{41}$ oxygen reduction reaction, ${ }^{42}$ and various hydrogenation ${ }^{43}$ and oxidation ${ }^{44,45}$ reactions. According to theoretical predictions the Au-shell Pd-core structure is the most thermodynamically favorable for $\mathrm{Pd}-\mathrm{Au} \mathrm{NPs},{ }^{\mathbf{4 6}}$ while a rich variety of Pd-Au NP structures has been detected experimentally. ${ }^{47-49}$ It is important to note that the surface composition of $\mathrm{Pd}-\mathrm{Au}$ systems may be altered by adsorbates such as CO and that even single Au or Pd atoms or dimers on the surface may significantly affect the overall catalytic performance of the system. ${ }^{\mathbf{5 0 - 5 3}}$

According to our analysis, the most significant contributions to the $E_{\mathrm{TOP}}$ (here and in the following discussion $E_{0}$ is subtracted from $E_{\mathrm{TOP}}$ ) for $\mathrm{Pd}_{70} \mathrm{Au}_{70} \mathrm{NP}$ come from stabilization of $\mathrm{Au}$ atoms on low-coordinated sites (Table 1). The lower coordination number of the site, the bigger is the energy gain: 200 $\mathrm{meV}$ for 9-coordinated terrace atoms of $\mathrm{Au}, 301 \mathrm{meV}$ for 7coordinated edge atoms, and $404 \mathrm{meV}$ for 6-coordinated corner atoms. The respective contributions to the global minimum energy calculated with the $E_{\text {TOP }}$ are $18 \%, 29 \%$ and $39 \%$ (Fig. 1). The energy of a Pd-Au bond is calculated by $E_{\mathrm{TOP}}$ to be only $\sim 13$ $\mathrm{meV}$; however, due to the large number of the heteroatomic bonds their contribution to the energy is sizeable, $14 \%$.

The chemical ordering of the lowest-energy homotop found for $\mathrm{Pd}_{70} \mathrm{Au}_{70}$ nicely reflects the magnitude of different terms in the topological energy expression (see Fig. 2). There, Au atoms occupy all the most energetically stable corner and edge positions and the remaining $\mathrm{Au}$ atoms are in surface terrace positions. The configuration of $\mathrm{Au}$ atoms on terraces may vary from facet to facet tending to maximize the number of $\mathrm{Pd}-\mathrm{Au}$ bonds. Note, however, that in the lowest-energy structure found by DFT there is only 260 heteroatomic bonds, while in the global minimum according to $E_{\mathrm{TOP}}$ it is 262 (Table 2). This finding reflects the expected presence of other minor contributions (of the order of $\delta=115 \mathrm{meV}$ ) to the $E_{\mathrm{ES}}$ that are not accounted for by the $E_{\mathrm{TOP}}$, eqn (1).

\section{Pd-Ag}

Pd-Ag alloys are studied mostly because of their potential applications as hydrogenation, ${ }^{54-57}$ fuel cell ${ }^{58}$ and other catalysts, ${ }^{59-61}$ sensors $^{62}$ and biosensors. ${ }^{63}$ Similarly to Pd-Au NPs, theoretical studies ${ }^{\mathbf{8 , 6 4}}$ predict Pd-core/Ag-shell structure of $\mathrm{Pd}-\mathrm{Ag}$ NPs and surface segregation of $\mathrm{Ag}$ was also observed experimentally. ${ }^{56,57,60}$ Interestingly, several experimental studies report homogeneous $\mathrm{Pd}-\mathrm{Ag}$ alloys ${ }^{59,62,65}$ or even $\mathrm{Pd}$-shell/Ag-core structures. ${ }^{58}$ It was also found that the surface segregation may be affected by the presence of adsorbates such as atomic H. ${ }^{57,66}$

Table 1 Descriptors ${ }^{a} \varepsilon_{i}$ in the topological energy expressions $E_{\mathrm{TOP}}$ eqn (1) for the $\mathrm{Pd}_{70} \mathrm{X}_{70}$ NPs (see Methodology part) with their precision, $\delta$, and accuracy, $\Delta E$, values (in $\mathrm{meV}$ ) and number of structures used for the fitting, $N_{\text {FIT }}$

\begin{tabular}{lllll}
\hline $\mathrm{X}$ & $\mathrm{Au}$ & $\mathrm{Ag}$ & $\mathrm{Cu}$ & $\mathrm{Zn}$ \\
\hline$\varepsilon_{\text {BOND }}^{\mathrm{Pd}-\mathrm{X}}$ & $-13_{-6}^{+4}$ & $-1_{-2}^{+2}$ & $-26_{-5}^{+5}$ & $-160_{-40}^{+52}$ \\
$\varepsilon_{\text {CORNER }}^{\mathrm{X}}$ & $-404_{-72}^{+76}$ & $-361_{-68}^{+50}$ & $95_{-33}^{+36}$ & $-251_{-342}^{+316}$ \\
$\varepsilon_{\text {EDGE }}^{\mathrm{X}}$ & $-301_{-77}^{+52}$ & $-289_{-129}^{+78}$ & $147_{-45}^{+46}$ & $-205_{-243}^{+280}$ \\
$\varepsilon_{\text {TERRACE }}$ & $-200_{-64}^{+52}$ & $-163_{-64}^{+43}$ & $183_{-40}^{+42}$ & $-90_{-234}^{+231}$ \\
$\varepsilon_{\text {LAYER }}$ & - & - & - & $-105_{-38}^{+29}$ \\
$N_{\text {FIT }}$ & 32 & 53 & 127 & 28 \\
$\delta$ & 115 & 150 & 360 & 348 \\
$\Delta E$ & 26 & 29 & 171 & 0
\end{tabular}

${ }^{a} 95 \%$ confidence intervals of $\varepsilon_{i}$ are also given, e.g. $-13_{-6}^{+4}$ means that the interval is -19 to -9 . 


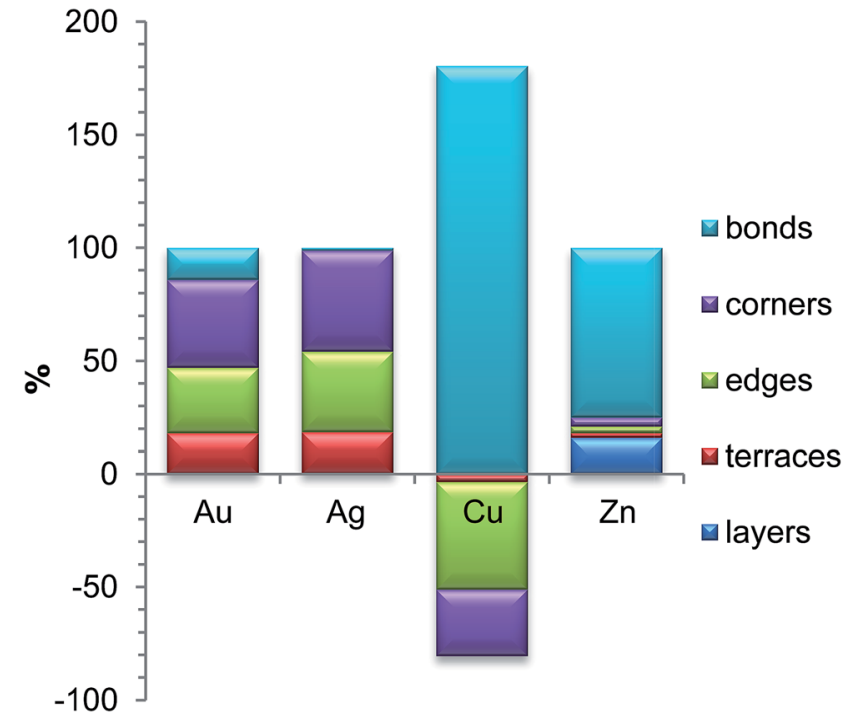

Fig. 1 Relative energy contributions (\%) to the global minima structures of $\mathrm{Pd}_{70} \mathrm{X}_{70}$ NPs according to the topological energy calculated as $\varepsilon_{i} N_{i} / \sum \varepsilon_{i} N_{i}$. Since in $\mathrm{Pd}-\mathrm{Cu}$ the only negative term is $\varepsilon_{\mathrm{BOND}}^{\mathrm{Pd} \text {-C }}$, the value of $\varepsilon_{\mathrm{BOND}}^{\mathrm{Pd}-\mathrm{Cu}} N_{\mathrm{BOND}} / \sum \varepsilon_{i} N_{i}$ exceeds $100 \%$.

We have found interactions in $\operatorname{Pd}_{70} \mathrm{Ag}_{70}$ to be quite similar to those in $\mathrm{Pd}_{70} \mathrm{Au}_{70}$ : the lower the coordination number of a site, the more energy is gained when it is occupied by an $\mathrm{Ag}$ atom. The most prominent contributions to the topological energy $E_{\text {TOP }}$ come from $\mathrm{Ag}$ atoms on corners (45\%), edges $(36 \%)$ and terraces (18\%) (Fig. 1). The energy of Pd-Ag bonds is calculated to be essentially zero $(-1 \pm 2 \mathrm{meV})$; thus, their contribution to $E_{\text {TOP }}$ does not exceed $1 \%$.

In line with the topological energy expression for PdAg, the structure of $\mathrm{Pd}_{70} \mathrm{Ag}_{70}$ with the lowest $E_{\mathrm{ES}}$ has all corner and edge positions occupied by silver atoms. The remaining $\mathrm{Ag}$ atoms are located on terraces, whereas the NP interior is composed of solely Pd (Fig. 2). The number of heteroatomic bonds in this structure is only 234 , i.e. significantly less than 262 in the global minimum for the respective $E_{\mathrm{TOP}}$. The reason for this difference is the negligible energy associated with $N_{\mathrm{BOND}}^{\mathrm{Pd}-\mathrm{Ag}}$, which probably compares in magnitude with other contributions to the $E_{\mathrm{ES}}$, not accounted for by the $E_{\mathrm{TOP}}$.

\section{$\mathbf{P d}-\mathbf{C u}$}

A lot of scientific effort has been devoted to $\mathrm{Pd}-\mathrm{Cu}$ alloys since they catalyze oxygen reduction reaction, ${ }^{67,68}$ O-enhanced watergas shift reaction (when supported on ceria), ${ }^{69,70}$ formic acid oxidation, ${ }^{71}$ water denitrification ${ }^{72-74}$ and several hydrogenation reactions. ${ }^{55,75,76}$ Early interatomic potential studies revealed two competing effects governing the structure of $\mathrm{Pd}-\mathrm{Cu}$ NPs: the tendency to maximize the number of heteroatomic bonds and the tendency of $\mathrm{Pd}^{77}$ or $\mathrm{Cu}^{78}$ to segregate on the surface. In some studies the enrichment of the surface by $\mathrm{Cu}$ or Pd was found to depend on their concentration. ${ }^{79}$ In those studies the most energetically stable NP structures also featured higher concentration of surface $\mathrm{Cu}$ atoms on corner and edge sites rather than on terrace sites. Experimentally $\mathrm{Pd}-\mathrm{Cu}$ NPs with $\mathrm{Cu}$-rich
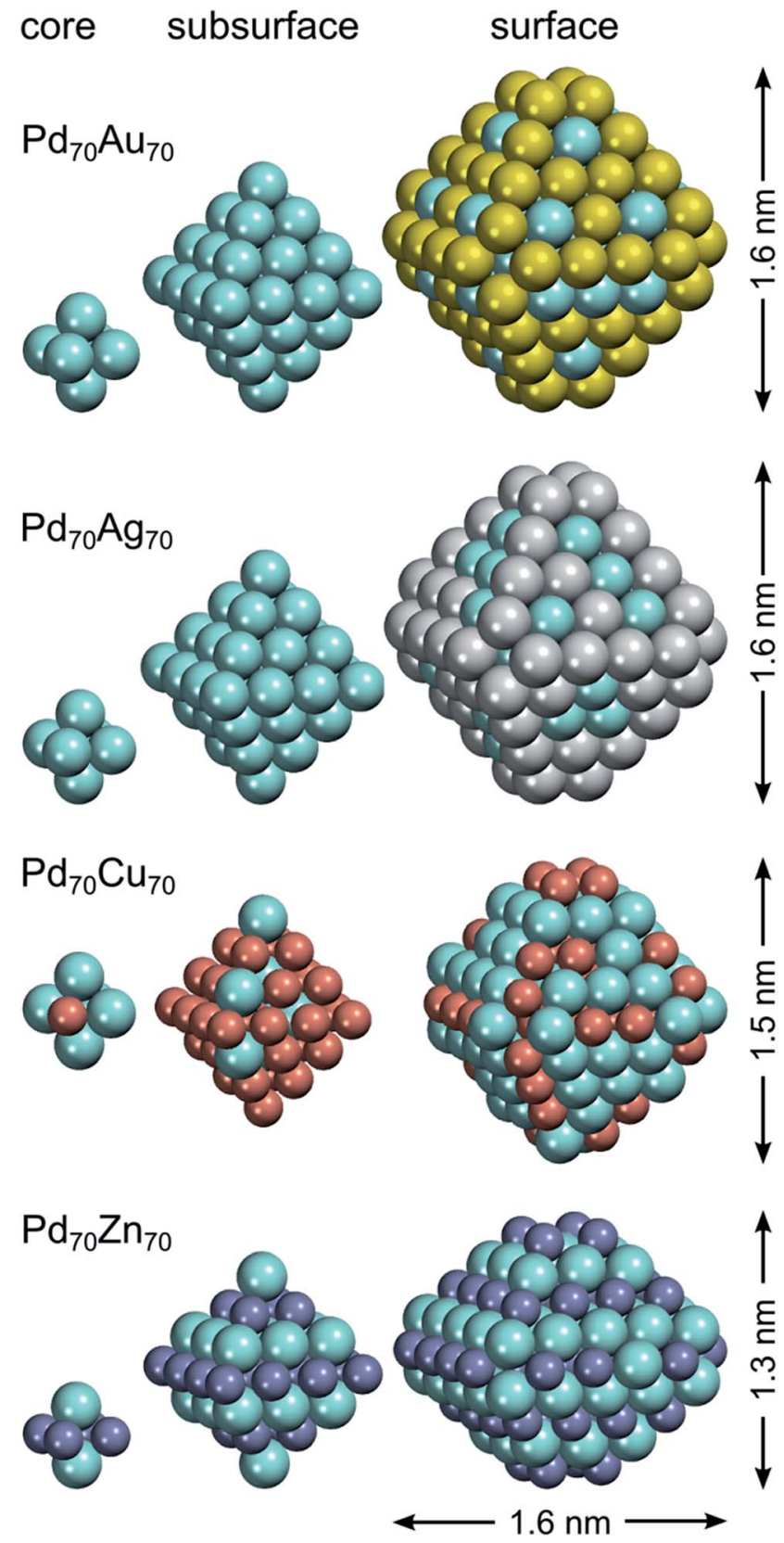

Fig. 2 Core, subsurface and surface shells of the lowest-energy $\mathrm{Pd}_{70} \mathrm{X}_{70}(\mathrm{X}=\mathrm{Au}, \mathrm{Ag}, \mathrm{Cu}, \mathrm{Zn}$ ) homotops according to density functional calculations. Spatial dimensions of the NPs are also indicated (for $\mathrm{Pd}_{70} \mathrm{Zn}_{70}$ the dimensions are given in two directions). $\mathrm{Pd}$ atoms are displayed as cyan spheres; atoms $X$ - as spheres of other colors.

surfaces $^{72,80}$ and well mixed ordered or disordered $\mathrm{Pd}-\mathrm{Cu}$ alloys $^{71,75,81}$ were characterized. Note that CO-induced surface segregation of $\mathrm{Pd}$ was documented for $\mathrm{Pd}-\mathrm{Cu}{ }^{\mathbf{8 0}}$

We consider chemical ordering in $\mathrm{Pd}-\mathrm{Cu}$ with fcc structure since for NPs of few $\mathrm{nm}$ it is more stable than bcc structure observed in $\mathrm{Pd}-\mathrm{Cu}$ bulk. ${ }^{78,82}$ The energetic stability of $\mathrm{Pd}-\mathrm{Cu}$ NPs comes mainly from the energy of heteroatomic bonds, which is twice of that in Pd-Au NPs (Table 1). Unlike the cases of $\mathrm{Pd}-\mathrm{Au}$ and $\mathrm{Pd}-\mathrm{Ag}, \mathrm{Cu}$ prefers to stay inside the NP, whereas the surface of $\mathrm{Pd}_{70} \mathrm{Cu}_{70}$ is enriched by $\mathrm{Pd}$. The reason is that $\mathrm{Pd}$ 
Table 2 Structural properties of the homotops $\mathrm{Pd}_{70} \mathrm{X}_{70}\left(\mathrm{X}=\mathrm{Au}, \mathrm{Ag}, \mathrm{Cu}, \mathrm{Zn}\right.$ ) with the lowest energies $E_{\mathrm{ES}}$ and $E_{\mathrm{TOP}}$. Average coordination numbers of $\mathrm{X}$ by $\mathrm{X}, N^{\mathrm{X}-\mathrm{X}}, \mathrm{X}$ by Pd, ${ }^{a} N^{\mathrm{Pd}-\mathrm{X}}$, and $\mathrm{Pd}$ by $\mathrm{Pd}, N^{\mathrm{Pd}-\mathrm{Pd}}$ are given to facilitate comparison with experimental (e.g. EXAFS) data

\begin{tabular}{|c|c|c|c|c|c|c|c|c|c|c|}
\hline $\mathrm{X}$ & & $N_{\text {BOND }}^{\mathrm{Pd}-\mathrm{X}}$ & $N_{\text {CORNER }}^{\mathrm{X}}$ & $N_{\text {EDGE }}^{\mathrm{X}}$ & $N_{\text {TERRACE }}^{\mathrm{X}}$ & $N_{\text {SUBSURFACE }}^{\mathrm{X}}$ & $N_{\text {CORE }}^{\mathrm{X}}$ & $N^{\mathrm{X}-\mathrm{X}}$ & $N^{\mathrm{Pd}-\mathrm{X}}$ & $N^{\mathrm{Pd}-\mathrm{Pd}}$ \\
\hline \multirow[t]{2}{*}{$\mathrm{Au}$} & ES & 260 & 24 & 24 & 22 & 0 & 0 & 3.57 & 3.71 & 7.17 \\
\hline & TOP & 262 & 24 & 24 & 22 & 0 & 0 & & & \\
\hline & TOP & 262 & 24 & 24 & 22 & 0 & 0 & & & \\
\hline \multirow[t]{2}{*}{$\mathrm{Cu}$} & ES & 358 & 16 & 17 & 1 & 35 & 1 & 4.20 & 5.11 & 3.69 \\
\hline & TOP & 382 & 12 & 14 & 8 & 34 & 2 & & & \\
\hline
\end{tabular}

${ }^{a}$ For NPs with $1: 1$ composition, the average coordination number of X by Pd equals the average coordination number of Pd by X. ${ }^{b}$ The same structure yields both the lowest $E_{\mathrm{ES}}$ and $E_{\mathrm{TOP}}$ for $\mathrm{Pd}_{70} \mathrm{Zn}_{70}$; in this structure $\sum_{\text {LAYERS }}\left|n_{i}^{\mathrm{Zn}}-n_{i}^{\text {Pd }}\right|$ equals to 136.

atoms are bigger than $\mathrm{Cu}$ atoms and, therefore, tend to segregate on the surface, where a part of the elastic stress is relieved..$^{77}$ Note, however, that the employed density functional (as well as other local and gradient-corrected functionals) also favors Pd segregation on the surface, since it predicts the surface energy of $\operatorname{Pd}(111)$ to be slightly smaller than the surface energy of $\mathrm{Cu}(111)$ in disagreement with experiments. ${ }^{32,109}$ Curiously, the order of stability of $\mathrm{Cu}$ in different positions, interior $>$ corner $>$ edge $>$ terrace, does not correlate with the coordination number of $\mathrm{Cu}$ in these sites. Since descriptors corresponding to $\mathrm{Cu}$ atoms on corner, edge and terrace positions are positive (reflecting that these positions are unstable for $\mathrm{Cu}$ with respect to interior ones), their destabilizing contributions to the $E_{\mathrm{TOP}}$ of the global minimum are $-29,-47$ and $-3 \%$, respectively. Hence, to counteract that the contribution of the heteroatomic bonds to $E_{\mathrm{TOP}}$ formally exceeds $100 \%$.

The descriptor value for Pd-Cu bonds, $-26_{-5}^{+5} \mathrm{meV}$ per bond, corresponds to the binding energy of $-104_{-20}^{+20} \mathrm{meV}$ per atom in (fcc or bcc) Pd-Cu bulk, which agrees with the experimental value of $-114 \mathrm{meV}$ per atom for the bcc alloy. ${ }^{83}$

The homotop with the lowest $E_{\mathrm{ES}}$ of the $\mathrm{Pd}_{70} \mathrm{Cu}_{70} \mathrm{NP}$ exhibits matryoshka-like (also called onion- or multishell-like) arrangement with Pd-rich surface shell, Cu-rich subsurface shell and Pd-rich core. This chemical ordering allows the formation of 358 heteroatomic bonds, while the number of $\mathrm{Cu}$ atoms is kept low on the surface, especially on terraces. The structure of the global minimum according to the $E_{\mathrm{TOP}}$ features even more heteroatomic bonds, 382, more $\mathrm{Cu}$ atoms on terraces and less $\mathrm{Cu}$ on edges and corners.

\section{Pd-Zn}

Bimetallic Pd-Zn is actively studied ${ }^{84-86}$ (often in the form of surface alloys ${ }^{87-89}$ ) because of its catalytic activity in (reverse) water-gas shift ${ }^{90-92}$ and hydrogenation reactions ${ }^{93}$ as well as potential application as selective and highly stable ${ }^{94,95}$ catalysts for methanol steam reforming. ${ }^{96-98}$ However, the employment of $\mathrm{Pd}-\mathrm{Zn}$ catalysts is complicated by the significant dependence of their properties on the $\mathrm{Zn}-\mathrm{Pd}$ ratio, ${ }^{91,99} \mathrm{NP}$ size $^{92}$ and the composition of the subsurface region..$^{98}$ Further complications come from strong dependence of the structure and composition of Pd-Zn systems on environmental conditions..$^{85,89,100}$
Both bulk and nanoparticulate $\mathrm{Pd}-\mathrm{Zn}$ are known to have tetragonally distorted $\mathbf{L} 1_{0}$ crystal structure ${ }^{101,102}$ without pronounced surface segregation of any component. ${ }^{87,94}$ Experimental interatomic distances in a distorted fcc-like bulk lattice of $1: 1 \mathrm{PdZn}$ are $\mathrm{Zn}-\mathrm{Zn}=\mathrm{Pd}-\mathrm{Pd}=289 \mathrm{pm}$ and $\mathrm{Pd}-\mathrm{Zn}=222$ pm. ${ }^{102}$ There, Pd and $\mathrm{Zn}$ atoms form monometallic layers and the distances between adjacent atoms in different layers are shorter than those within the same layer. The clear propensity of $\mathrm{Pd}_{70} \mathrm{Zn}_{70}$ NPs to build alternating Pd and $\mathrm{Zn}$ layers normal to one of the [001], [010] or [001] directions (equivalent in the fcc lattice) accompanied by NP compression along this direction is revealed by DFT calculations and topological ordering optimizations (Fig. 2). Energy of such compression is properly taken into account by the term $\varepsilon_{\text {LAYER }} N_{\text {LAYER }}$ in eqn (1). It noticeably increases the $E_{\mathrm{TOP}}$ precision for $\mathrm{Pd}_{70} \mathrm{Zn}_{70}$ from $1294 \mathrm{meV}$ to 348 $\mathrm{meV}$ (the accuracy $\Delta E$ is 0 , even when this term is neglected in the $E_{\mathrm{TOP}}$ expression). For alloys that do not tend to form layered structures, the term $\varepsilon_{\mathrm{LAYER}} N_{\mathrm{LAYER}}$ does not improve the $E_{\mathrm{TOP}}$ precision or may be even somewhat detrimental due to overfitting. For instance, for $\mathrm{Pd}_{70} \mathrm{Cu}_{70}$ excluding that contribution from $E_{\mathrm{TOP}}$ increases precision of the latter by $16 \%$.

Heteroatomic bonds in Pd-Zn NPs are found to be an order of magnitude stronger than those in the other investigated alloys. This difference reflects the fact that composites of $\mathrm{Au}, \mathrm{Ag}$, $\mathrm{Cu}$ with Pd are alloys of d-elements, while $\mathrm{Zn}$ is an sp-element. Strong heteroatomic Pd-Zn bonds of polar character (the charge separation is estimated to range from $\mathrm{Pd}^{-0.2} \mathrm{Zn}^{+0.2}$ to $\left.\mathrm{Pd}^{-0.4} \mathrm{Zn}^{+0.4}\right)^{11,102}$ result in the prevalence of ordered structures of $\mathrm{Pd}-\mathrm{Zn}$ in the phase diagram. ${ }^{85}$ On the contrary, alloys of $\mathrm{d}$ elements are more prone to exhibit more random crystal structures, where the number of heteroatomic bonds is not maximal. Hence, $\mathrm{Pd}-\mathrm{Zn}$ is better classified as an intermetallic compound rather than a bimetallic alloy. ${ }^{103}$

In line with these considerations, the dominant $E_{\mathrm{TOP}}$ contribution for $\mathrm{Pd}_{70} \mathrm{Zn}_{70}$ is given by $\mathrm{Pd}-\mathrm{Zn}$ bonds. The descriptor $\varepsilon_{\mathrm{BOND}}^{\mathrm{Pd}-\mathrm{Zn}}=-160_{-40}^{+52} \mathrm{meV}$ yields the alloy formation energy of $-640_{-160}^{+208} \mathrm{meV}$ per atom, in agreement with the measured value of $-520 \mathrm{meV}$ per atom. ${ }^{104}$ Hence, heteroatomic bonds define $75 \%$ of the $E_{\mathrm{TOP}}$ of the global minimum, while the rest comes mostly from the energy associated with the formation of the layered structure (16\%). Despite that the energies of 
$\mathrm{Zn}$ atoms on low-coordinated sites are only slightly smaller than the respective energies of $\mathrm{Ag}$ atoms in $\mathrm{Pd}_{70} \mathrm{Ag}_{70}$, their overall contribution is rather small (9\%) compared to that of $\mathrm{Pd}-\mathrm{Zn}$ bonds. Since the relative energies of $\mathrm{Pd}_{70} \mathrm{Zn}_{70}$ NPs do not strongly depend on the number of low-coordinated $\mathrm{Zn}$ atoms (compared to other characteristics), it is hard to accurately fit the respective descriptors. Therefore, the formal statistical inaccuracy of $\varepsilon_{\text {CORNER }}^{\mathrm{Zn}}, \varepsilon_{\mathrm{EDGE}}^{\mathrm{Zn}}$ and $\varepsilon_{\text {TERRACE }}^{\mathrm{Zn}}$ exceeds $100 \%$. Yet, this does not seem to affect the overall accuracy of the proposed approach, because these descriptors appear to be less important for the description of Pd-Zn NPs. To examine how sensitive the chemical ordering in the obtained global minimum is to the statistical inaccuracy of the descriptors for $\mathrm{Pd}_{70} \mathrm{Zn}_{70}$ (Table 1), its chemical ordering was re-optimized with 10 other sets of descriptors. These sets were generated by fixing each one of the 5 descriptors at the lowest or the highest value of its $95 \%$ confidence interval and re-fitting all other descriptors using the same homotops as the training set. Despite substantial variations of descriptors produced in such a way, global optimizations with all these 10 sets yielded the homotop with the same $N_{i}$ characteristics as in the homotop presented in Fig. 2 and Table 2.

The structures with the lowest $E_{\mathrm{ES}}$ and $E_{\mathrm{TOP}}$ are the same for $\mathrm{Pd}_{70} \mathrm{Zn}_{70}$ NPs due to the high accuracy of the topological energy expression. They feature the maximum possible number of heteroatomic bonds, 422 , for the $\mathrm{A}_{70} \mathrm{~B}_{70} \mathrm{NP}$ of the considered shape. The $N_{\text {LAYER }}$ value is also the maximum possible, 136, for this particular stoichiometry and shape. As already mentioned, the energies of $\mathrm{Zn}$ atoms on the low-coordinated sites are of minor importance for the determination of the most stable $\mathrm{Pd}_{70} \mathrm{Zn}_{70}$ homotops. Hence, the amounts of $\mathrm{Zn}$ atoms on various types of low-coordinated sites have intermediate values. All in all, the most energetically stable homotop exhibits the layered $\mathbf{L} 1_{0}$ structure, similar to PdZn bulk. Nevertheless, this structure also exposes Pd atoms on $\mathrm{Zn}$-composed edges, due to the slight excess of Pd for the formation of perfect layered structure. Unlike monolayer thick Pd-Zn films on $\mathrm{Pd}(111),{ }^{89}$ no zigzag-like structures are seen on $\{111\}$ facets of $\mathrm{Zn}_{70} \mathrm{Pd}_{70}$ particles.

Note that for $\mathrm{Pd}_{70} \mathrm{Zn}_{70}$ NP one could construct a homotop apparently very similar to the obtained global minimum by exchanging all $\mathrm{Zn}$ atoms with all $\mathrm{Pd}$ atoms at once. This homotop has the same number of heteroatomic bonds and the same layered structure as the global minimum, but fewer $\mathrm{Zn}$ atoms on corners and edges and more $\mathrm{Zn}$ atoms on terraces. Therefore, its $E_{\mathrm{ES}}\left(E_{\mathrm{TOP}}\right)$ is $1765 \mathrm{meV}$ (1389 meV) higher than that of the global minimum displayed in Fig. 2. Despite the apparent similarity, for the simulation code this homotop looks absolutely different compared to the global minimum structure, since the position of every atom has changed. The transition from one homotop to another via exchange of one random $\mathrm{Zn}$ atom with a random $\mathrm{Pd}$ atom at a time would go through the configurations with rather small amount of $\mathrm{Pd}-\mathrm{Zn}$ bonds and, therefore, very high relative energy. In practice, it was impossible to overcome the transition state between these two homotops via single exchange moves even at Monte-Carlo simulation temperatures as high as $10000 \mathrm{~K}$. However, the transformation between the discussed homotop and the global minimum does not pose any difficulty when multiple exchange moves are applied, that is, $n$ random atoms are exchanged at a time (see Methodology). This illustrates the efficiency of the employed computational scheme, which we believe is sufficient to ensure that the lowest-energy structures from the MonteCarlo simulations are indeed the global minima within the studied topological framework.

\section{Thermal energies}

Naturally, a system in thermodynamic equilibrium adopts exclusively its global minimum configuration only at zero Kelvin, while at any finite temperature the presence of other homotops is possible with a probability determined by the Boltzmann factor. The configurational space of $\mathrm{Pd}_{70} \mathrm{Au}_{70}$, $\mathrm{Pd}_{70} \mathrm{Ag}_{70}$ and $\mathrm{Pd}_{70} \mathrm{Cu}_{70}$ NPs features many homotops different from the global minima only by the number of heteroatomic bonds. The energies of these homotops are just slightly higher than the energies of the corresponding global minima and hence the population of these homotop states is notable even at relatively low temperatures. Consequently, these homotops can contribute to the thermal energy.

It is very instructive to compare the thermal energy accumulated by chemical (dis-)ordering to the precision $\delta$ of the topological expressions (Table 1). For example, the $\mathrm{Pd}_{70} \mathrm{Au}_{70} \mathrm{NP}$ obtains (homotopic) thermal energy of $115 \mathrm{meV}$ already at $\sim 140$ $\mathrm{K}$ (that is, at this temperature the average energy of the system in our Monte-Carlo simulations is $115 \mathrm{meV}$ above the energy of the global minimum). Therefore, despite that the structure of $\mathrm{Pd}_{70} \mathrm{Au}_{70}$ with the lowest found $E_{\mathrm{ES}}$ (Fig. 2) may not yet be the global minimum for the chosen ES computational scheme, it is certainly feasible at $140 \mathrm{~K}$ and may serve as a representative model for the NP at this and higher temperatures. In a similar way one gets that the considered lowest-energy structure of the $\mathrm{Pd}_{70} \mathrm{Ag}_{70}$ is a representative homotop at $\sim 360 \mathrm{~K}$, while for $\mathrm{Pd}_{70} \mathrm{Cu}_{70}$ this temperature is $\sim 220 \mathrm{~K}$.

Unlike the aforementioned three nanoalloys, PdZn features strong heteroatomic bonds with $\varepsilon_{\text {BOND }}^{\mathrm{Pd}-\mathrm{Zn}}$ of $160 \mathrm{meV}$. Thus, there are not many low-energy homotops around the global minimum. In fact, the second most stable structure has the energy $E_{\text {TOP }} \sim 205 \mathrm{meV}$ higher than the global minimum. Therefore, below $500 \mathrm{~K}$ essentially the global minimum structure alone is present in the thermodynamic ensemble. Much higher temperatures are required to populate less stable homotop states, so the (homotopic) thermal energy reaches the precision of the topological expression, $348 \mathrm{meV}$, only at $\sim 1300$ K. Thus, this high temperature is related mostly to the propensity of $\mathrm{Pd}-\mathrm{Zn}$ to form regular nanostructures and to avoid any disorder, rather than to the low precision of the $E_{\mathrm{TOP}}$ for this system. Note that $\mathrm{Zn}$ evaporates from Pd-Zn surface alloys at temperatures above $800 \mathrm{~K} \cdot{ }^{105}$ Therefore, it is safe to assume a very small degree of disorder in experimental samples of Pd-Zn close to the thermodynamic equilibrium.

\section{Mixing energies}

Another way to quantify the binding strength of the metals $\mathrm{A}$ and $\mathrm{B}$ in $\mathrm{A}_{Y} \mathrm{~B}_{N-Y}$ NPs is by means of their mixing energy (per atom): 


$$
E^{\mathrm{MIX}}=\left[N E\left(\mathrm{~A}_{Y} \mathrm{~B}_{N-Y}\right)-Y E\left(\mathrm{~A}_{N}\right)-(N-Y) E\left(\mathrm{~B}_{N}\right)\right] / N^{2},
$$

where $E\left(\mathrm{~A}_{Y} \mathrm{~B}_{N-Y}\right)$ is the total energy of the $\mathrm{A}_{Y} \mathrm{~B}_{N-Y} \mathrm{NP}$ and $E\left(\mathrm{~A}_{N}\right)$, $E\left(\mathrm{~B}_{N}\right)$ are the energies of respective monometallic NPs with the same structure optimized with the same plane-wave basis cutoff as the $\mathrm{A}_{Y} \mathrm{~B}_{N-Y} \mathrm{NP}$. Thus, e.g. for $\mathrm{Pd}_{70} \mathrm{Zn}_{70}$ the NPs $\mathrm{Zn}_{140}$ and $\mathrm{Pd}_{140}$ with fcc structure were considered as energy references. According to this definition negative $E_{\mathrm{MIX}}$ values mean exothermic mixing. Since the presented approach allows calculating total energies of alloy NPs with precision $\delta$, the respective precision of the calculated mixing energy per atom is $\delta / N$.

The mixing energies (per atom) of the homotops with the lowest energy $E_{\mathrm{ES}}$, calculated using the respective topological expression and DFT are presented in Table 3 (see also Table S1 $\dagger$ ). The magnitudes of ES mixing energies are found to be $\sim 110 \mathrm{meV}$ for Pd-Au, Pd-Ag and Pd-Cu NPs, while for Pd-Zn it is almost $500 \mathrm{meV}$. The magnitudes of $E_{\mathrm{TOP}}^{\mathrm{MIX}}$ energies resemble the respective $E_{\mathrm{ES}}^{\mathrm{MIX}}$ values, except the case of Pd-Ag, for which $E_{\mathrm{TOP}}^{\mathrm{MIX}}$ is almost twice smaller than $E_{\mathrm{ES}}^{\mathrm{MIX}}$. The reason is that the topological energy expression for $\mathrm{Pd}-\mathrm{Ag}$ assigns almost zero energy to the heteroatomic $\mathrm{Pd}-\mathrm{Ag}$ bonds and consequently predicts their essentially vanishing contribution to the mixing energy. In the rather similar $\mathrm{Pd}_{70} \mathrm{Au}_{70} \mathrm{NP}$ heteroatomic bonds are responsible for $30 \%$ of the mixing energy calculated using $E_{\mathrm{TOP}}$, which can explain the $33 \%$ difference between $E_{\mathrm{TOP}}^{\mathrm{MIX}}$ for $\mathrm{Pd}-\mathrm{Au}$ and Pd-Ag.

\section{Dependency of descriptors on the composition and the size of nanoparticles}

For practical purposes it is very important to know if descriptors obtained for one system can also be used to represent a slightly different system. For instance, one may wonder if descriptors calculated for smaller NPs yield reasonable results when applied to bigger species, for which ES calculations are unfeasible. To evaluate the dependency of descriptors on the size and the composition of NPs we constructed $E_{\mathrm{TOP}}$ expressions and performed optimization of chemical ordering in $\operatorname{Pd}_{Y} \mathrm{Au}_{79-Y}(Y=$ $6,28,40,53,71)$ and $\operatorname{Pd}_{Y} \mathrm{Au}_{140-Y}(Y=11,20,30,35,40,49,70$, $91,126)$ NPs. The results are summarized in Fig. 3 , where the error bars represent $60 \%$ confidence intervals of the $\varepsilon_{i}$ calculated via the bootstrap analysis. Note that if such confidence intervals for two $\varepsilon_{i}$ values do not overlap, the probability that these descriptors are not different is less than $((1-0.6) / 2)^{2}=$ $4 \%$.

Table 3 Mixing energies ${ }^{a} E^{\mathrm{MIX}}$ (per atom, in meV) of the $\mathrm{Pd}_{70} \mathrm{X}_{70}$ homotops with the lowest calculated energy $E_{\mathrm{ES}}$

\begin{tabular}{lllll}
\hline $\mathrm{NP}$ & $\mathrm{Pd}_{70} \mathrm{Au}_{70}$ & $\mathrm{Pd}_{70} \mathrm{Ag}_{70}$ & $\mathrm{Pd}_{70} \mathrm{Cu}_{70}$ & $\mathrm{Pd}_{70} \mathrm{Zn}_{70}$ \\
\hline$E_{\mathrm{ES}}^{\mathrm{MIX}}$ & $-109_{-1}^{+1}$ & $-108_{-1}^{+1}$ & $-119_{-3}^{+3}$ & $-498_{-2}^{+2}$ \\
$E_{\mathrm{TOP}}^{\mathrm{MIX}}$ & $-82_{-15}^{+15}$ & $-55_{-10}^{+10}$ & $-89_{-13}^{+14}$ & $-484_{-135}^{+100}$
\end{tabular}

${ }^{a}$ The $95 \%$ confidence intervals for $E_{\mathrm{ES}}^{\mathrm{MIX}}$ were calculated as $\delta$ divided by the number of atoms in the NP; the $95 \%$ confidence intervals for $E_{\mathrm{TOP}}^{\mathrm{MIX}}$ were calculated with the bootstrap analysis.

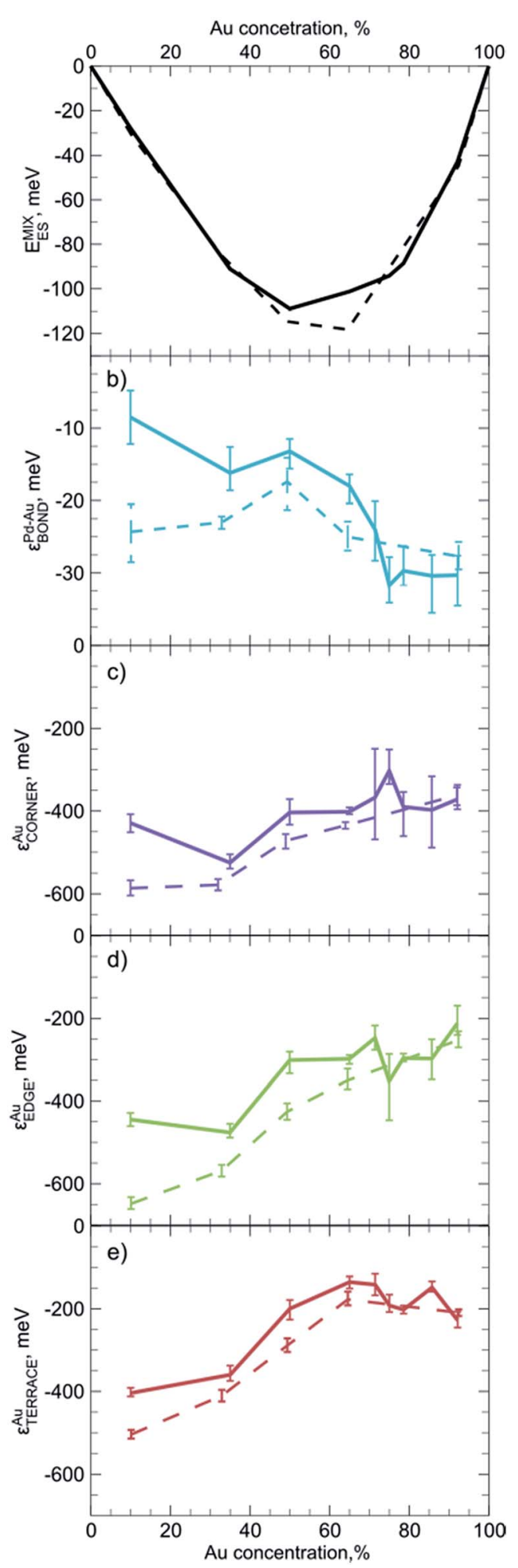

Fig. 3 Dependency on the NP composition of (a) ES calculated mixing energy per atom, and of the descriptors (b) $\varepsilon_{\mathrm{BOND}}^{\mathrm{Au}-\mathrm{Pd}}$, (c) $\varepsilon_{\mathrm{CORNER}}^{\mathrm{Au}}$, (d) $\varepsilon_{\mathrm{EDGE}}^{\mathrm{Au}}$, (e) $\varepsilon_{\text {TERRACE }}$ in $E_{\text {TOP }}$ for $\mathrm{Pd}_{140-Y} \mathrm{Au}_{Y}$ (solid line) and $\mathrm{Pd}_{79-Y} \mathrm{Au}_{Y}$ (dashed line) NPs. Error bars represent $60 \%$ confidence intervals.

The first observation is that the descriptors (and the mixing energies) significantly depend on the composition of the NPs. That is, the binding in Pd-rich Pd-Au NPs is quite different from 
that in Au-rich NPs. The latter feature stronger heteroatomic bonds, but less stable gold atoms on surface sites compared to Pd-rich NPs. These differences are probably related to the gradual changes in the electronic structure and average interatomic distances in the NPs with growing Au content. In most cases quantitative changes of the descriptors do not cause qualitative changes in the NP ordering. The only exception is that at very low $\mathrm{Au}$ concentrations $\mathrm{Au}$ atoms seem to prefer to occupy edges rather than corners of the Pd-Au NPs. This effect is more pronounced for $\operatorname{Pd}_{Y} \mathrm{Au}_{79-Y}$ than for $\operatorname{Pd}_{Y} \mathrm{Au}_{140-Y}$ NPs. The change in the relative stability of corner and edge positions for $\mathrm{Au}$ is reflected in the structure of the respective global minima.

A similar phenomenon was mentioned in a previous study of $\mathrm{Pd}_{Y} \mathrm{Au}_{79-Y} \mathrm{NPs}^{33}{ }^{33}$ Nevertheless, Pd-Au NPs prepared by galvanic displacement expose $\mathrm{Au}$ atoms on corners rather than on edges. ${ }^{49}$ However, according to our calculations corners are the most stable positions for Au only at moderate and high $\mathrm{Au}$ concentrations. The inconsistency between the presented and experimental results may also be due to kinetic limitations in the experimental setup or deficiencies of the employed exchange-correlation density functional.

One notices a rather limited dependency of the descriptors $\varepsilon_{i}$ and the mixing energies per atom on the NP size. Especially at high $\mathrm{Au}$ concentrations, differences between $\varepsilon_{i}$ values for $\operatorname{Pd}_{Y}$ $\mathrm{Au}_{79-Y}$ and $\operatorname{Pd}_{Y} \mathrm{Au}_{140-Y}$ are barely visible and they are often within the statistical accuracy of the calculations. However, at lower $\mathrm{Au}$ content the binding was found to be slightly stronger in the smaller NPs. In numerous cases it was shown that many observables of NPs bigger than $1.5 \mathrm{~nm}$ already depend rather smoothly on their size and start to converge to a certain value. ${ }^{29,30,106}$ Hence, it is probable that the descriptors calculated for $\mathrm{Pd}_{Y} \mathrm{Au}_{140-Y}$ as well as for other $\mathrm{Pd}_{70} \mathrm{X}_{70}$ NPs may serve as a reasonable approximation for descriptors of bigger NPs or, at least, they will lead to qualitatively correct chemical ordering, when applied to bigger NPs. At the same time, descriptors may not work satisfactorily for very small bimetallic clusters, where the quantum nature of interatomic interaction is expected to be notable. Our findings suggest that it is more important to use descriptors tailored for appropriate particle composition than for its exact size.

One may ask, to what extent applications of the present topological method can be limited to such high-symmetry "magic" shapes of bimetallic crystallites, as truncated octahedral ones discussed so far. To address this question we optimized the chemical ordering in a fcc NP $\mathrm{Pd}_{61} \mathrm{Au}_{61}$ of just $C_{3 \mathrm{v}}$ symmetry (see ESI $\dagger$ ) with a shape reminiscent of typical shapes of supported Pd NPs. ${ }^{28}$ The individual topological descriptors, the overall picture of interactions as well as the chemical ordering in $\mathrm{Pd}_{61} \mathrm{Au}_{61}$ are very similar to those of the highly symmetric truncated octahedral NP $\operatorname{Pd}_{70} \mathrm{Au}_{70}$. The accuracy $\Delta E$ and precision $\delta$ values of the $E_{\mathrm{TOP}}$ expressions for $\mathrm{Pd}_{61} \mathrm{Au}_{61}$ and $\mathrm{Pd}_{70} \mathrm{Au}_{70}$ are also very close. These findings strongly suggest that the method is applicable to reliably describe chemical ordering also in nanocrystallites with rather unsymmetrical shapes.

\section{Extrapolation to the $4.4 \mathrm{~nm}$ large nanoparticles}

Benefiting from the rather moderate dependency of descriptors on NP size, we can apply the descriptors calculated for $\mathrm{Pd}_{70} \mathrm{X}_{70}$ NPs to bigger $\sim 4.4 \mathrm{~nm} \operatorname{Pd}_{732} \mathrm{X}_{731}$ NPs as an illustrative example
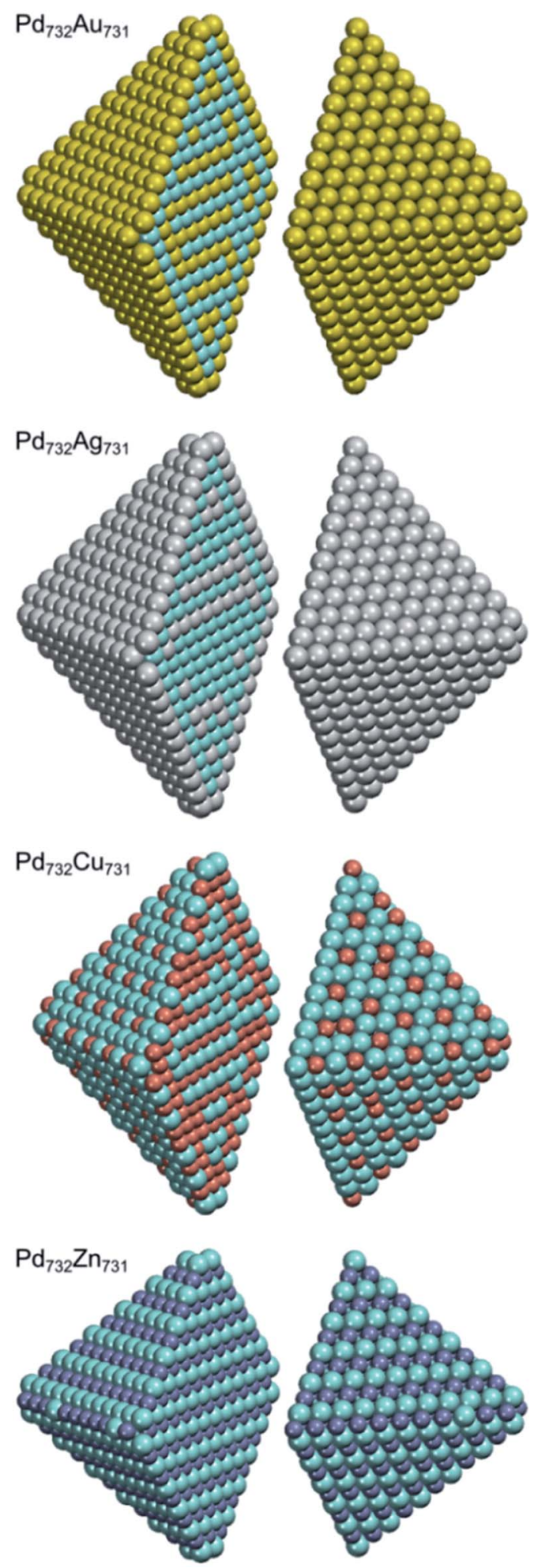

Fig. 4 Structures of $\mathrm{Pd}_{732} \mathrm{X}_{731}(\mathrm{X}=\mathrm{Au}, \mathrm{Ag}, \mathrm{Cu}$ and $\mathrm{Zn})$ NPs with optimized chemical ordering. $\mathrm{Pd}$ atoms are displayed as cyan spheres; elements $X-$ as spheres of other colors. 
(see Fig. 4). The shape of these NPs is chosen to mimic the shape of $\mathrm{Pd}_{70} \mathrm{X}_{70}$ NPs, i.e. featuring small $\{100\}$ facets composed of only four atoms. To simulate NPs with bigger $\{100\}$ facets one would need to calculate the descriptor for X atoms on $\{100\}$ terraces, which are absent in our $\mathbf{M}_{\mathbf{1 4 0}}$ models. Mind that using the proposed $E_{\mathrm{TOP}}$ expression we were able to perform efficient simulations of such $\sim 4.4 \mathrm{~nm}$ NPs with the speed of $>10^{7}$ MonteCarlo steps per hour on one Intel $2.66 \mathrm{GHz}$ processor.

Both $\mathrm{Pd}_{732} \mathrm{Au}_{731}$ and $\mathrm{Pd}_{732} \mathrm{Ag}_{731}$ NPs have surfaces covered by $\mathrm{Au}$ and $\mathrm{Ag}$, respectively. In turn, their subsurface shells are composed mostly of Pd atoms and only two Au or three Ag atoms, which allows the maximization of the number of heteroatomic bonds. Consequently, the cores of the NPs have stoichiometries of $\mathrm{Pd}_{332} \mathrm{Au}_{157}$ and $\mathrm{Pd}_{333} \mathrm{Ag}_{156}$. In order to maximize the number of heteroatomic bonds these $\operatorname{Pd}_{0.68} \mathrm{X}_{0.32}$ cores also develop $\mathrm{L} 1_{0}$-like structure with partially formed layers of $\mathrm{Au}$ or $\mathrm{Ag}$ in Pd. The structure of the Pd-Cu NPs is more complicated due to two competing tendencies: maximization of $N_{\mathrm{BOND}}^{\mathrm{Pd}-\mathrm{Cu}}$ and bulk segregation of $\mathrm{Cu}$. As a result, the surface shell has a stoichiometry of $\mathrm{Pd}_{412} \mathrm{Cu}_{160}$ and exhibits abundant $\mathrm{Cu}$ monomers as well as occasionally present $\mathrm{Cu}$ dimers on terraces and edges. Each corner of the NP has two $\mathrm{Cu}$ atoms on the opposite vertices of the small $\{100\}$ facet. The subsurface shell of the NP is enriched in $\mathrm{Cu}$ (stoichiometry $\mathrm{Pd}_{87} \mathrm{Cu}_{315}$ ). Finally, the NP core has almost 1:1 stoichiometry, $\mathrm{Pd}_{233} \mathrm{Cu}_{256}$, and again features layer-like structure. As for the global minimum of $\mathrm{Pd}_{732} \mathrm{Zn}_{731}$, quite expectedly, it has almost a bulk-cut structure similarly to the $\mathrm{Pd}_{70} \mathrm{Zn}_{70}$ case.

\section{Conclusions}

We propose a method to optimize chemical ordering in bimetallic NPs using an energy expression related to topological degrees of freedom, $E_{\text {TOP. }}$. This expression depends on the topology of bonds between the atoms composing the NP, but not on the explicit coordinates of these atoms. Using this approach we optimized the chemical ordering in truncated octahedral $\mathrm{Pd}_{Y} \mathrm{Au}_{79-Y}$ and $\mathrm{Pd}_{Y} \mathrm{Au}_{140-Y}$ NPs as well as in $\mathrm{Pd}_{70} \mathrm{Ag}_{70}$ and $\mathrm{Pd}_{70} \mathrm{Cu}_{70}$ NPs with fcc lattices and $\mathrm{Pd}_{70} \mathrm{Zn}_{70}$ with $\mathrm{L} 1_{0}$ lattice; the chemical ordering in the fcc nanocrystal $\operatorname{Pd}_{61} \mathrm{Au}_{61}$ with a less symmetric shape has been also determined. We emphasize that this approach can be applied to bimetallics of any given lattice type, up to the point, when the structure becomes strongly disordered, e.g. at higher temperatures or in conceivable cases of particularly big irregular lattice distortions for some combinations of metals.§

For every NP size and composition descriptors in the $E_{\mathrm{TOP}}$ expression were fitted to the energies of more than 20 NP structures obtained via density functional calculations. The precision of the topological description tailored in such a way (i.e. their ability to predict results of the electronic structure calculations) was $115-360 \mathrm{meV}$ for $\mathrm{Pd}_{70} \mathrm{X}_{70}$ NPs ( $\mathrm{X}=\mathrm{Au}, \mathrm{Ag}, \mathrm{Cu}$ and $\mathrm{Zn}$ ) and the accuracy of the $E_{\mathrm{TOP}}$ was at least twice better. For the $\mathrm{Pd}-\mathrm{Au}, \mathrm{Pd}-\mathrm{Ag}$, and $\mathrm{Pd}-\mathrm{Cu}$ NPs the precision of the topological approach is comparable to the thermal energy associated with the population of low-energy homotops at temperatures of 140-360 K. Therefore, even if some of the lowest-energy homotops found here are not exactly the lowestenergy ones (according to electronic structure calculations), they are representative homotops at very moderate temperatures.

A very useful advantage of the proposed approach is that the descriptors $\varepsilon_{i}$ in the $E_{\text {TOP }}$ expression have a clear physical meaning, e.g. the energy of heteroatomic bonds or the relative energy of $\mathrm{X}$ atoms on terrace, edge or corner positions of the NP (interior positions being the reference). Thus, the overall binding energy is inherently a sum of contributions from particular structural features. In turn, changes of these contributions from system to system reflect changes in their properties. Analyzing the structure of the topological energy expression we were able to get valuable insights into the binding in $\mathrm{Pd}-\mathrm{Au}, \mathrm{Pd}-\mathrm{Ag}, \mathrm{Pd}-\mathrm{Cu}$ and $\mathrm{Pd}-\mathrm{Zn}$ nanoalloys. Note that available experimental formation energies of bulk $1: 1 \mathrm{PdCu}$ and PdZn agree well with the descriptor values $\varepsilon_{\text {BOND }}^{\mathrm{Pd}-\mathrm{X}}$ of heteroatomic bonds for $\mathrm{Pd}_{70} \mathrm{Cu}_{70}$ and $\mathrm{Pd}_{70} \mathrm{Zn}_{70}$ NPs, respectively. The analysis of descriptors for $\operatorname{Pd}_{Y} \mathrm{Au}_{79-Y}$ and $\operatorname{Pd}_{Y} \mathrm{Au}_{140-Y} \mathrm{NPs}$ showed a notable dependency on the composition of the NPs, but much smaller dependency on their size. This allows one to use descriptors based on electronic structure calculations of relatively small NPs of e.g. 140 atoms to optimize chemical ordering in bigger species formed of thousands of atoms. Hence, we applied our method to describe the chemical ordering in large $\mathrm{Pd}_{732} \mathrm{X}_{731}(\mathrm{X}=\mathrm{Au}, \mathrm{Ag}, \mathrm{Cu}$ and $\mathrm{Zn})$ NPs, which are beyond the scale of conventional density functional calculations.

The optimization of Pd-Au and Pd-Ag NPs with $E_{\text {TOP }}$ yields $\mathrm{Au}$ and $\mathrm{Ag}$ atoms preferentially occupying positions with lower coordination numbers. The energy gain due to the formation of heteroatomic bonds is rather small for these materials and plays a secondary role in the determination of the NP ordering. On the contrary, the energy of heteroatomic bonds is the driving force for the alloying of $\mathrm{Cu}$ and $\mathrm{Pd}$. In this case, the stability of $\mathrm{Cu}$ atoms is the highest inside the NP and the lowest on NP terraces. These two effects lead to the matryoshka-like structure of the lowest-energy $\mathrm{Pd}_{70} \mathrm{Cu}_{70}$ homotop, which has the surface shell enriched with $\mathrm{Pd}$, the subsurface region enriched with $\mathrm{Cu}$ and the core composed mostly of Pd.

Unlike bimetallic $\mathrm{Pd}-\mathrm{Au}, \mathrm{Pd}-\mathrm{Ag}$ and $\mathrm{Pd}-\mathrm{Cu}$ alloys formed by d-elements, the binding in intermetallic Pd-Zn involves the interaction of a noble d-metal with an sp-element. The result is a much higher energy gain due to the formation of $\mathrm{Pd}-\mathrm{Zn}$ bonds and a much higher (in magnitude) mixing energy of Pd-Zn NPs compared to other considered nanoalloys. The preferential occupation of any particular type of sites by $\mathrm{Zn}$ atoms is much less important for the NP structure and energy in this case. The structure of the most energetically stable homotop is very close to the cut from bulk $\mathrm{Pd}-\mathrm{Zn}$ with $\mathrm{L} 1_{0}$ crystal structure. Just like the bulk, it features alternating Pd and Zn layers and tetragonal distortion. The term in the $E_{\text {TOP }}$ expression related to the formation of such a layered structure turned out to be responsible for $16 \%$ of the binding in Pd-Zn NPs.

The proposed method for the optimization of the chemical ordering in bimetallic particles paves the way to atomistic studies of several nanometer big bimetallic crystallites with 
known lattice structure. Fortunately, the latter can be determined by contemporary experimental techniques. Notably, the present new approach may be straightforwardly augmented for applications to heterometallic nanocrystals on a support or in a reaction atmosphere.

\section{Methods}

Electronic structure calculations were performed with the periodic plane-wave code VASP. ${ }^{107}$ We used the $\operatorname{PBE}^{108}$ exchange-correlation functional found to be one of the most appropriate common functionals for the description of transition metals. ${ }^{109,110}$ The interaction between valence and core electrons was treated within the projector augmented wave approach. To moderate computational expenditures we carried out calculations with the 250-280 eV energy cut-off of planewave basis sets, which yielded results very close to those obtained with the cut-off $415 \mathrm{eV}$ (Table S1†). The one-electron levels were smeared by $0.1 \mathrm{eV}$ using the first-order method of Methfessel and Paxton; ${ }^{\mathbf{1 1 1}}$ finally, converged energies were extrapolated to the zero smearing. Calculations were performed only at the $\Gamma$-point in the reciprocal space. All atoms were allowed to move (relax) during the geometry optimization until forces on them became less than $0.2 \mathrm{eV} \mathrm{nm}^{-1}$. The minimal separation between NPs exceeded $0.7 \mathrm{~nm}$, at which the interaction between adjacent NPs was found to be negligible. ${ }^{28,36}$

\section{Acknowledgements}

This study was supported by the European Commission (FP7NMP.2012.1.1-1 project ChipCAT, Ref. 310191 and COST Actions MP0903 and CM0904), the Spanish MINECO (grant CTQ2012-34969) and the Generalitat de Catalunya (projects 2014SGR97 and XRQTC). Financial support from the Spanish MEDU is gratefully acknowledged by SMK (FPU grant AP20093379). The authors thank the Red Española de Supercomputación for provided computer resources and technical assistance.

\section{Notes and references}

\footnotetext{
\$ For the sake of brevity, we refer to the optimization of chemical ordering within a fixed NP lattice as global optimization and to the ordering that yields the lowest energy within this lattice as the global minimum.

$\S$ Note added in proof: Recently the present method has been used to determine chemical ordering of Pt-Co nanoparticles prepared by magnetron sputtering. ${ }^{\mathbf{1 1 2}}$ There, applicability of the method to accurately describe chemical ordering of magnetic alloy particles composed of metals with notably different atomic radii was demonstrated.
}

1 F. Calvo, Nanoalloys from Fundamentals to Emergent Applications, Elsevier, Amsterdam, 2013.

2 R. Ferrando, J. Jellinek and R. L. Johnston, Chem. Rev., 2008, 108, 845-910.

3 S. Heiles and R. L. Johnston, Int. J. Quantum Chem., 2013, 113, 2091-2109.

4 D. Wang, H. L. Xin, R. Hovden, H. Wang, Y. Yu, D. A. Muller, F. J. DiSalvo and H. D. Abruña, Nat. Mater., 2013, 12, 81-87.
5 D. Bochicchio and R. Ferrando, Phys. Rev. B: Condens. Matter Mater. Phys., 2013, 87, 165435.

6 D. Schebarchov and D. J. Wales, J. Chem. Phys., 2013, 139, 221101.

7 F. Calvo, Faraday Discuss., 2008, 138, 75-88.

8 G. G. Rondina and J. L. F. Da Silva, J. Chem. Inf. Model., 2013, 53, 2282-2298.

9 R. Marchal, A. Genest, S. Krüger and N. Rösch, J. Phys. Chem. C, 2013, 117, 21810-21822.

10 F. Calvo and C. Mottet, Phys. Rev. B: Condens. Matter Mater. Phys., 2011, 84, 035409.

11 K. M. Neyman, R. Sahnoun, C. Inntam, S. Hengrasmee and N. Rösch, J. Phys. Chem. B, 2004, 108, 5424-5430.

12 S. M. Kozlov, G. F. Cabeza and K. M. Neyman, Chem. Phys. Lett., 2011, 506, 92-97.

13 J. Kleis, J. Greeley, N. A. Romero, V. A. Morozov, H. Falsig, A. H. Larsen, J. Lu, J. J. Mortensen, M. Dułak, K. S. Thygesen, J. K. Nørskov and K. W. Jacobsen, Catal. Lett., 2011, 141, 1067-1071.

14 G. Barcaro, A. Fortunelli, M. Polak and L. Rubinovich, Nano Lett., 2011, 11, 1766-1769.

15 M. Alcantara Ortigoza and T. S. Rahman, Phys. Rev. B: Condens. Matter Mater. Phys., 2008, 77, 195404.

16 M. Molayem, V. G. Grigoryan and M. Springborg, J. Phys. Chem. C, 2011, 115, 7179-7192.

17 D. Bochicchio and R. Ferrando, Nano Lett., 2010, 10, 42114216.

18 K. Laasonen, D. Bochicchio, E. Panizon and R. Ferrando, J. Phys. Chem. C, 2013, 117, 26405-26413.

19 Y. Wang and M. Hou, J. Phys. Chem. C, 2012, 116, 1081410818.

20 L. O. Paz-Borbón, R. L. Johnston, G. Barcaro and A. Fortunelli, J. Phys. Chem. C, 2007, 111, 2936-2941.

21 F. R. Negreiros, Z. Kuntova, G. Barcaro, G. Rossi and A. Fortunelli, J. Chem. Phys., 2010, 132, 234703.

22 G. Barcaro, R. Ferrando, A. Fortunelli and G. Rossi, J. Phys. Chem. Lett., 2010, 1, 111-115.

23 M. Polak and L. Rubinovich, Phys. Chem. Chem. Phys., 2014, 16, 1569-1575.

24 M. Mueller, P. Erhart and K. Albe, Phys. Rev. B: Condens. Matter Mater. Phys., 2007, 76, 155412.

25 F. Lequien, J. Creuze, F. Berthier, I. Braems and B. Legrand, Phys. Rev. B: Condens. Matter Mater. Phys., 2008, 78, 075414.

26 K. Binder and E. Luijten, Phys. Rep., 2001, 344, 179-253.

27 G. L. W. Hart, V. Blum, M. J. Walorski and A. Zunger, Nat. Mater., 2005, 4, 391-394.

28 S. M. Kozlov, H. A. Aleksandrov, J. Goniakowski and K. M. Neyman, J. Chem. Phys., 2013, 139, 084701.

29 S. M. Kozlov, H. A. Aleksandrov and K. M. Neyman, J. Phys. Chem. C, 2014, 118, 15242-15250.

30 S. M. Kozlov and K. M. Neyman, Top. Catal., 2013, 56, 867873.

31 L. Vitos, A. V. Ruban, H. L. Skriver and J. Kollár, Surf. Sci., 1998, 411, 186-202.

32 F. R. de Boer, R. Boom, W. C. M. Mattens, A. R. Miedema and A. K. Niessen, Cohesion in Metals, North-Holland, Amsterdam, 1988. 
33 I. V. Yudanov and K. M. Neyman, Phys. Chem. Chem. Phys., 2010, 12, 5094-5100.

34 P. Wessa, Free Statistics Software, version 1.1.23-r7, Office for Research Development and Education, 2014, http:// www.wessa.net/.

35 A. C. Davison and D. V. Hinkley, Bootstrap Methods and their Application, Cambridge University Press, Cambridge, 1997.

36 F. Viñes, F. Illas and K. M. Neyman, Angew. Chem., Int. Ed., 2007, 46, 7094-7097.

37 A. Wang, X. Y. Liu, C.-Y. Mou and T. Zhang, J. Catal., 2013, 308, 258-271.

38 G. J. Hutchings and C. J. Kiely, Acc. Chem. Res., 2013, 46, 1759-1772.

39 J. K. Edwards, B. Solsona, E. N. N, A. F. Carley, A. A. Herzing, C. J. Kiely and G. J. Hutchings, Science, 2009, 323, 10371041.

40 M. H. Ab Rahim, M. M. Forde, R. L. Jenkins, C. Hammond, Q. He, N. Dimitratos, J. A. Lopez-Sanchez, A. F. Carley, S. H. Taylor, D. J. Willock, D. M. Murphy, C. J. Kiely and G. J. Hutchings, Angew. Chem., Int. Ed., 2013, 52, 1280-1284.

41 R. Nath Dhital, S. Karanjit, C. Kamonsatikul and H. Sakurai, J. Am. Chem. Soc., 2012, 134, 20250-20253.

42 M. Nie, P. K. Shen and Z. Wei, J. Power Sources, 2007, 167, 69-73.

43 N. E. Kolli, L. Delannoy and C. Louis, J. Catal., 2013, 297, 79-92.

44 M. Nie, H. Tang, Z. Wei, S. P. Jiang and P. K. Shen, Electrochem. Commun., 2007, 9, 2375-2379.

45 D. I. Enache, J. K. Edwards, P. Landon, B. Solsona-Espriu, A. F. Carley, A. A. Herzing, M. Watanabe, C. J. Kiely, D. W. Knight and G. J. Hutchings, Science, 2006, 311, 362365.

46 L. O. Paz-Borbón, R. L. Johnston, G. Barcaro and A. Fortunelli, J. Chem. Phys., 2008, 128, 134517.

47 R. C. Tiruvalam, J. C. Pritchard, N. Dimitratos, J. A. LopezSanchez, J. K. Edwards, A. F. Carley, G. J. Hutchings and C. J. Kiely, FaradayDiscuss., 2011, 152, 63-86.

48 A. Bruma, R. Ismail, L. O. Paz-Borbón, H. Arslan, G. Barcaro, A. Fortunelli, Z. Y. Li and R. L. Johnston, Nanoscale, 2013, 5, 646-652.

49 H. Zhang, T. Watanabe, M. Okumura, M. Haruta and N. Toshima, Nat. Mater., 2012, 11, 49-52.

50 J. Zhang and A. N. Alexandrova, J. Phys. Chem. Lett., 2013, 4, 2250-2255.

51 F. Gao, Y. Wang and D. W. Goodman, J. Phys. Chem. C, 2010, 114, 4036-4043.

52 P. Han, S. Axnanda, I. Lyubinetsky and D. W. Goodman, J. Am. Chem. Soc., 2007, 129, 14355-14361.

53 F. Gao, Y. Wang and D. W. Goodman, J. Phys. Chem. C, 2009, 113, 14993-15000.

54 Q. Zhang, J. Li, X. Liu and Q. Zhu, Appl. Catal., A, 2000, 197, 221-228.

55 S. K. Kim, J. H. Lee, I. Y. Ahn, W.-J. Kim and S. H. Moon, Appl. Catal., A, 2011, 401, 12-19.

56 A. Pachulski, R. Schödel and P. Claus, Appl. Catal., A, 2011, 400, 14-24.
57 A. Yarulin, I. Yuranov, F. Cárdenas-Lizana, D. T. L. Alexander and L. Kiwi-Minsker, Appl. Catal., A, 2014, 478, 186-193.

58 K. Tedsree, T. Li, S. Jones, C. W. A. Chan, K. M. K. Yu, P. A. J. Bagot, E. A. Marquis, G. D. W. Smith and S. C. E. Tsang, Nat. Nanotechnol., 2011, 6, 302-307.

59 Y. Lu and W. Chen, ACS Catal., 2012, 2, 84-90.

60 H. Rong, S. Cai, Z. Niu and Y. Li, ACS Catal., 2013, 3, 15601563.

61 L. Li, M. Chen, G. Huang, N. Yang, L. Zhang, H. Wang, Y. Liu, W. Wang and J. A. Gao, J. Power Sources, 2014, 263, 13-21.

62 Q. Wang, J. Zheng and H. Zhang, J. Electroanal. Chem., 2012, 674, 1-6.

63 H. Wang, Y. Zhang, H. Li, B. Du, H. Ma, D. Wu and Q. Wei, Biosens. Bioelectron., 2013, 49, 14-19.

64 F. R. Negreiros, G. Barcaro, Z. Kuntová, G. Rossi, R. Ferrando and A. Fortunelli, Surf. Sci., 2011, 605, 483-488.

65 W. He, X. Wu, J. Liu, W. Zhou, X. Hu and S. Xie, Chem. Mater., 2010, 22, 2988-2994.

66 S. González, K. M. Neyman, S. Shaikhutdinov, H.-J. Freund and F. Illas, J. Phys. Chem. C, 2007, 111, 6852-6856.

67 F. Fouda-Onana, S. Bah and O. Savadogo, J. Electroanal. Chem., 2009, 636, 1-9.

68 L. Zhang and G. Henkelman, J. Phys. Chem. C, 2012, 116, 20860-20865.

69 J. Kugai, J. T. Miller, N. Guo and C. Song, Appl. Catal., B, 2011, 105, 306-316.

70 J. Kugai, J. T. Miller, N. Guo and C. Song, J. Catal., 2011, 277, 46-53.

71 L. Lu, L. Shen, Y. Shi, T. Chen, G. Jiang, C. Ge, Y. Tang, Y. Chen and T. Lu, Electrochim. Acta, 2012, 85, 187-194.

72 U. Matatov-Meytal and M. Sheintuch, Catal. Commun., 2009, 10, 1137-1141.

73 O. S. G. P. Soares, J. J. M. Órfão and M. F. R. Pereira, Appl. Catal., B, 2009, 91, 441-448.

74 Q. Zhang, L. Ding, H. Cui, J. Zhai, Z. Wei and Q. Li, Appl. Surf. Sci., 2014, 308, 113-120.

75 M. Friedrich, S. A. Villaseca, L. Szentmiklósi, D. Teschner and M. Armbrüster, Materials, 2013, 6, 2958-2977.

76 G. Kyriakou, M. B. Boucher, A. D. Jewell, E. A. Lewis, T. J. Lawton, A. E. Baber, H. L. Tierney, M. FlytzaniStephanopoulos and E. C. H. Sykes, Science, 2012, 335, 1209-1211.

77 J. M. Montejano-Carrizales, M. P. Iniguez and J. A. Alonso, Phys. Rev. B: Condens. Matter Mater. Phys., 1994, 49, 16649-16658.

78 L. Zhu, K. S. Liang, B. Zhang, J. S. Bradley and A. E. DePristo, J. Catal., 1997, 167, 412-416.

79 L. Yang, Philos. Mag. A, 2000, 80, 1879-1888.

80 J. S. Bradley, E. W. Hill, B. Chaudret and A. Duteil, Langmuir, 1995, 11, 693-695.

81 M. Friedrich and M. Armbrüster, Chem. Mater., 2009, 21, 5886-5891.

82 V. Shah and L. Yang, Philos. Mag. A, 1999, 79, 2025-2049.

83 R. Hultgren, P. D. Desai, D. T. Hawkins, M. Gleiser and K. Kelley, Selected Values of Thermodynamic Properties of 
Binary Alloys, American Society for Metals, Russell Township, 1973.

84 K. Föttinger, Catal. Today, 2013, 208, 106-112.

85 M. Armbrüster, M. Behrens, K. Föttinger, M. Friedrich, É. Gaudry, S. K. Matam and H. R. Sharma, Catal. Rev., 2013, 55, 289-367.

86 S. M. Kozlov, H. A. Aleksandrov, L. V. Moskaleva, M. Bäumer and K. M. Neyman, in Comprehensive Inorganic Chemistry, ed. J. Reedijk and K. Poeppelmeier, Elsevier, Amsterdam, 2nd edn, 2013, vol. 7, Surface Inorganic Chemistry and Heterogeneous Catalysis, ed. R. Schlögl and J. W. Niemantsverdriet, pp. 475-503.

87 Z.-X. Chen, K. M. Neyman and N. Rösch, Surf. Sci., 2004, 548, 291-300.

88 A. Bayer, K. Flechtner, R. Denecke, H.-P. Steinrück, K. M. Neyman and N. Rösch, Surf. Sci., 2006, 600, 78-94.

89 C. Weilach, S. M. Kozlov, H. H. Holzapfel, K. Föttinger, K. M. Neyman and G. Rupprechter, J. Phys. Chem. C, 2012, 116, 18768-18778.

90 R. A. Dagle, A. Platon, D. R. Palo, A. K. Datye, J. M. Vohs and Y. Wang, Appl. Catal., A, 2008, 342, 63-68.

91 L. Bollmann, J. L. Ratts, A. M. Joshi, W. D. Williams, J. Pazmino, Y. V. Joshi, J. T. Miller, A. J. Kropf, W. N. Delgass and F. H. Ribeiro, J. Catal., 2008, 257, 43-54.

92 V. Lebarbier, R. Dagle, A. Datye and Y. Wang, Appl. Catal., A, 2010, 379, 3-6.

93 M. W. Tew, H. Emerich and J. A. van Bokhoven, J. Phys. Chem. C, 2011, 115, 8457-8465.

94 T. Conant, A. M. Karim, V. Lebarbier, Y. Wang, F. Girgsdies and A. Datye, J. Catal., 2008, 257, 64-70.

95 Q. Zhang and R. J. Farrauto, Appl. Catal., A, 2011, 395, 6470.

96 N. Iwasa, S. Masuda, N. Ogawa and N. Takezawa, Appl. Catal., A, 1995, 125, 145-157.

97 N. Iwasa and N. Takezawa, Top. Catal., 2003, 22, 215-216.
98 C. Rameshan, W. Stadlmayr, C. Weilach, S. Penner, H. Lorenz, M. Hävecker, R. Blume, T. Rocha, D. Teschner, A. Knop-Gericke, R. Schlögl, N. Memmel, D. Zemlyanov, G. Rupprechter and B. Klötzer, Angew. Chem., Int. Ed., 2010, 49, 3224-3227.

99 M. Friedrich, D. Teschner, A. Knop-Gericke and M. Armbrüster, J. Catal., 2012, 285, 41-47.

100 K. Föttinger, J. A. van Bokhoven, M. Nachtegaal and G. Rupprechter, J. Phys. Chem. Lett., 2011, 2, 428-433.

101 S. Penner, B. Jenewein, H. Gabasch, B. Klötzer, A. KnopGericke, R. Schlögl and K. Hayek, J. Catal., 2006, 241, 14-19.

102 M. Friedrich, A. Ormeci, Y. Grin and M. Armbrüster, Z. Anorg. Allg. Chem., 2010, 636, 1735-1739.

103 Some researchers find the notation $\mathrm{Zn}-\mathrm{Pd}$ (with the positively charged atom mentioned first) to be more appropriate than Pd-Zn.

104 S. Kou and Y. A. Chang, Acta Metall., 1975, 23, 1185-1190. 105 H. Gabasch, A. Knop-Gericke, R. Schlögl, S. Penner, B. Jenewein, K. Hayek and B. Klötzer, J. Phys. Chem. B, 2006, 110, 11391-11398.

106 A. Roldán, F. Viñes, F. Illas, J. M. Ricart and K. M. Neyman, Theor. Chem. Acc., 2008, 120, 565-573.

107 G. Kresse and J. Furthmuller, Phys. Rev. B: Condens. Matter Mater. Phys., 1996, 54, 11169-11186.

108 J. P. Perdew, K. Burke and M. Ernzerhof, Phys. Rev. Lett., 1996, 77, 3865-3868.

109 P. Janthon, S. M. Kozlov, F. Viñes, J. Limtrakul and F. Illas, J. Chem. Theory Comput., 2013, 9, 1631-1640.

110 P. Janthon, S. A. Luo, S. M. Kozlov, F. Viñes, J. Limtrakul, D. G. Truhlar and F. Illas, J. Chem. Theory Comput., 2014, 10, 3832-3839.

111 M. Methfessel and A. T. Paxton, Phys. Rev. B: Condens. Matter Mater. Phys., 1989, 40, 3616-3621.

112 G. Kovács, S. M. Kozlov, I. Matolínová, M. Vorokhta, V. Matolín and K. M. Neyman, Phys. Chem. Chem. Phys., 2015, 17, DOI: 10.1039/C5CP01070E. 